\title{
Ornithology Research: present and future
}

\author{
Sandra Maria Hartz ${ }^{1}\left(\mathbb{C} \cdot\right.$ Leandro Bugoni $^{2}(\mathbb{D}$
}

Published online: 1 March 2022

(c) The Author(s), under exclusive licence to Sociedade Brasileira de Ornitologia 2022

We are pleased to present the Volume 30 of Ornithology Research, with a new editor-in-chief, Dr. Sandra Hartz. Since 2020, when Ornithol. Res. started to be published in partnership with Springer-Nature, it has been increasingly recognized in the ornithology community as a leading publication in the Neotropical region. Bugoni (2020) presented a comprehensive review of the long history and key steps of the journal, with the first volume edited in 1990 as Ararajuba, and later as Revista Brasileira de Ornitologia. Bugoni worked as editor for 6 years through the journal (2016-2021) implementing several changes and moving Ornithol. Res. towards a new standard level.

In these 2 years as Ornithology Research in the new format, we expanded the visibility of the journal globally, and the overall level of submissions has substantially increased. We received 224 manuscripts since then, with several still under review, and had published 70 papers. Figure 1 presented the analysis of all papers published in the journal within the last two years, using scientific words appearing in paper titles and the free software https://www.wordclouds. $\mathrm{com} /$. We can identify some patterns regarding the articles published in Ornithology Research: (1) Most studies are still from Brazil, despite the journal is open to, and intend to expand to cover the entire Neotropical region, as well as studies from all continents; (2) Papers are usually focused on species rather than on subjects (e.g., extinction, dispersion, diversity, conservation, phylogeny); (3) Natural history studies, and then several on breeding biology as the leading topic. Such straightforward analysis suggests that there is an avenue for growth in several areas, within the journal's scope.

This is the current Ornithology Research reality. How about the future? We will work to increase the international relevance of the journal, with associate editors from all continents. Targets include reduction on the review time, from submission to first decision, which already had been reduced substantially in comparison with the period before 2020 . We especially welcome articles that develop new concepts, reviews, and methods and identify general patterns, with continued attention to good studies on life history, filling gaps in our current knowledge of basic biology of bird species in the wild. We hope that the increase of the impact factor in comparison to Rev. Bras. Ornitol. (which reached over

Sandra Maria Hartz

sandramariahartz@gmail.com

1 Biosciences Institute, Ecology Department, Universidade

Federal do Rio Grande do Sul - UFRGS, Av. Bento

Gonçalves, 9500, Porto Alegre, RS 91501-970, Brazil

2 Institute of Biological Sciences, Waterbirds and Sea Turtles Laboratory, Universidade Federal do Rio Grande - FURG, Av. Itália s/n, Campus Carreiros, Rio Grande, RS 96203-900, Brazil 
Fig. 1 Word cloud analyses of papers published in Ornithology Research in 2020 and 2021

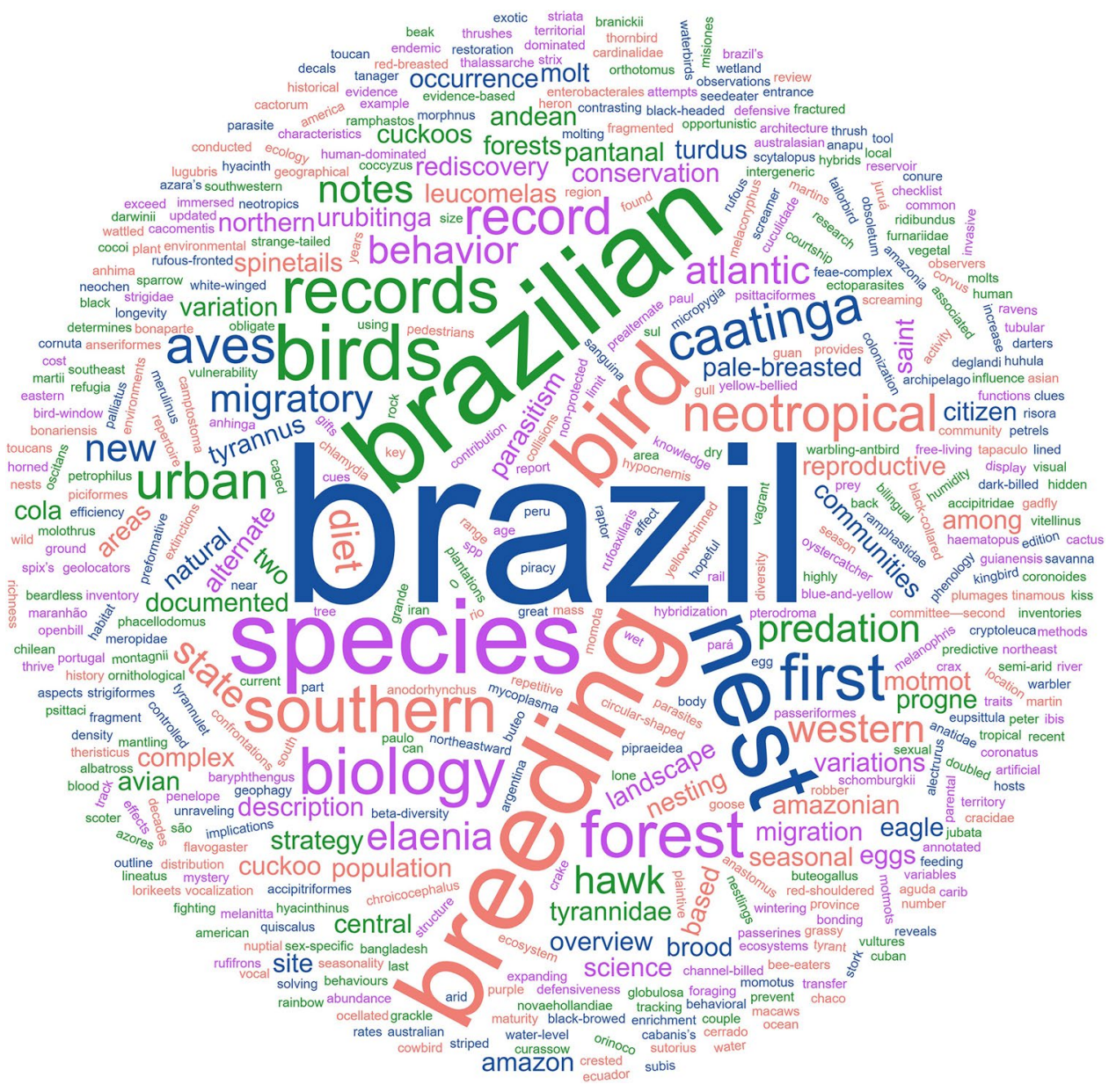

$0.5)$, expect to be received by mid-2022, will also encourage authors to submit their best manuscripts to Ornithology Research.

A good journal is made by dedicated people, and then, we thank the whole Springer-Nature staff, as well as associate editors, reviewers, and authors for the continued support, keeping the journal on track. Enjoy reading this and the future volumes of Ornithology Research.
Acknowledgements The authors are grateful to Paula Flores in helping with the figure. SMH is grateful to Brazilian Ornithological Society for the invitation to take the position of Editor-in-Chief.

\section{References}

Bugoni L (2020) From Ararajuba to Ornithology Research: an historical overview of bird journals published by the Brazilian Ornithological Society. Ornithol Res 28:1-3. https://doi.org/10.1007/ s43388-020-00001-6 